\title{
Reflections on collectively working toward sustainability: indicators for indicators!
}

\author{
D. M. Freebairn ${ }^{\mathrm{A}, \mathrm{C}}$ and C.A. King ${ }^{\mathrm{B}}$ \\ A Department of Natural Resources and Mines, PO Box 318, Toowoomba, Qld 4350, Australia. \\ ${ }^{\mathrm{B}}$ Department of Primary Industries, PO Box 102, Toowoomba, Qld 4350, Australia. \\ ${ }^{\mathrm{C}}$ Author for correspondence; e-mail: david.freebairn@nrm.qld.gov.au
}

\begin{abstract}
A variety of indicators have been developed and applied by farmers and scientists for the northern cereal belt. A general overview is presented of 'What are we trying to monitor?' followed by some example concepts; erosion hazard, salinity hazard, nutrient balance, production efficiency and participatory learning. These examples illustrate the complexity of indicator application and their dependence on context, purpose and scale. Emphasis is given to providing a rationale for developing indicators that focus on 'soft' system status (e.g. behaviour) as well as 'hard' system status. The propositions put forward are that indicators need to be integrated with the development of improved management systems, and that land managers (and community) as a collective, are key to this process. Some frequently asked questions about indicator development and application are responded to. Some 'Indicators for Indicators' that we have found useful in aiding indicator development, particularly in participatory fora are presented.
\end{abstract}

Additional keywords: farming systems, sustainability indicators, soft systems, participatory development, resource management.

\section{Introduction}

It can be argued that indicators have been used for centuries. For example, Ho Chi, a Chinese agriculturalist and philosopher some 4000 years ago laid out the basic components required for sustainable production: create level land for cultivation, return waste to the field, maintain trees in the landscape, do not over irrigate and plant a mix of species. Today, these correspond to concerns for water and wind erosion, nutrient balance, salinity, disease management and biodiversity.

The label 'indicators', however, is recent in research, development and extension (RD\&E) policy and practice across the globe. In Australia, agricultural and resource management RD\&E organisations have been trying to implement the use of sustainability indicators in rural areas in the past decade. So why is it that indicators have become so popular? Some key motivations include: (i) accountability for science, extension and agricultural practice; (ii) changing societal values which influence market preferences and demands; (iii) corresponding national and global policies (e.g. Kyoto greenhouse protocols); (iv) the demand from farm families and industry for improved farm management aids; (v) learning (e.g. the result of a change in either knowledge, attitudes, skills, aspirations or practice); (vi) genuine altruism and stewardship - striving for excellence.

King et al. (2000) provide a summary of what they term 'the Indicator Industry', showing that the reasons why indicators of sustainability have been and still are being developed are plentiful; illustrating numerous frameworks and criteria that have been suggested to develop and select indicators. They list a variety of end users and put forward a number of reasons as to why indicators are not being effectively used for the purposes they have been developed.

Their review on sustainability indicators presented general concepts and conclusions about indicator development and use. These include:

Indicators have been predominantly: discipline based, point sourced, monitored in a static context, and measured in absolute terms;

Indicator development has been predominantly: reductionist in nature, focused at regional, state and national levels, carried out by the scientific community, and has neglected end users in the development process;

Indicator use has been predominantly based on an adoption by end users paradigm, content orientated and ignorant of farmer knowledge - a one-way transfer of technology.

In this paper we would like to extend the arguments put forward by King et al. (2000) and suggest how and why indicator development and use could proceed. We present our own experiences with the development and application of a variety of indicators by farmers and scientists using the northern cereal belt as a case study. In many cases the distinction of who developed the indicator or for what purpose is unclear (and is likely to remain this way). Our 
view is that for the purposes of this paper, the origins and intents of previously developed indicators are not as important as what we do with them now.

In addition, we see the example indicators presented in this paper as perspectives - examples of opportunities for anyone wishing to explore indicators as management tools to guide learning amongst farmers, scientists and the community. We take the view that farm managers want to make a profit, but also need to be more accountable to the general public. In addition, we suggest that most farmers have a genuine interest in and would like to obtain environmentally and socially acceptable farming systems.

To begin, a general overview is presented of 'What have we been trying to monitor, traditionally and more recently?' in the northern cereal belt. Some example indicators that have assisted understanding and monitoring are illustrated in more detail. These indicators consider the broad issues of erosion hazard, salinity hazard, nutrient balance, production efficiency and more recently, participatory learning. The main conclusion that can be drawn from these examples is that there is much complexity in indicator application. Indicators are most often context, purpose and scale dependent.

Second, we address some frequently asked questions about indicator development and application. These include: (i) Why have indicators? (ii) Who are we developing indicators for? (iii) How should indicators be developed? (iv) Should indicators aim to be general or specific? (v) Can a single indicator be used at different levels of scale? (vi) Are farmer-developed indicators rigorous? (vii) How can indicators address short-term and long-term considerations? (viii) What makes a good indicator?

Finally, a variety of 'indicators for indicators' are presented that we have found useful in aiding indicator development, particularly in participatory fora. Our experiences range either from facilitating or participating in; on-station and on-farm participatory research, indicator development workshops, focus groups, consultancies, and the development of systems models with farmers or scientists. Our experiences presented in this paper have focused on the northern cereal region (northern New South Wales and Queensland). We do not propose that the details should be broadly applicable, although the principle should have generality. The ideas we present are somewhat retrospective and are offered as 'food for thought' to purposefully inform the development and use of indicators in the future (by the land manager through to policy application).

\section{What have we 'traditionally' monitored?}

In the northern cereal belt, indicators have primarily focused on measuring biophysical status, particularly in relation to the productivity of land and water. In this context, the concept of renewable and non-renewable resources deserves a mention. It can be argued that reversible changes in a resource are not of great concern to policy development, with an assumption that market forces will provide a means for balancing inputs and outputs, with dynamic equilibrium being achieved. On the other hand, non-renewable resources can be considered community assets that require public attention and monitoring. In some cases, market failure results in both renewable and non-renewable resources being neglected by land managers and policy. Stoneham et al. (2002) refer to non-renewable stocks of capital (e.g. land) and reproducible capital (e.g. knowledge) and their role in achieving sustainable development at the broad scale in Australian agriculture.

Typically, agricultural resources have been categorised in terms of natural resources and production potential. Production efficiency is a measure of how well the natural resources, water (rainfall or irrigation) and land (soil), are managed to produce useful products. Generally water can be treated as a renewable resource; however, soil is generally regarded as being economically non-renewable (although many aspects of soil quality are certainly renewable or repairable).

Resource efficiency can likewise be used to describe how natural resources respond to management. Thus, the stability of production and resource condition integrate management and environment. Scale of study varies from a basic management unit, a paddock, through to catchment, regional and national responses. In terms of auditing requirements, changes in production efficiency and resource condition are generally masked by weather variability and technological improvements.

Productivity decline in the northern cereal belt is generally attributed to the following: (i) erosion (wind, water) leading to a loss of plant water-holding capacity and nutrients; (ii) soil structure decline leading to decreased infiltration, increased runoff and soil loss; (iii) fertility decline; (iv) increased acidity and salinity; (v) contamination of soil and products; (vi) loss of flexibility in agricultural operations through increased development of resistance to pesticides.

Some example indicators that have assisted understanding and monitoring in the northern cereal belt are illustrated below in more detail. Comments on where they might be extrapolated up in scale to meet the needs of government are also included. These fall into the broad categories of erosion hazard, salinity hazard, nutrient balance and production efficiency. In addition to these, we include the category of financial performance to represent a further interest in the northern cereal belt on financial status as well as biophysical status. The examples illustrate the complexity of their application in practice at a variety of levels.

\section{Erosion hazard}

High soil erosion rates and associated poor water quality are regarded as major natural resource management challenges for the northern cereal region. A mix of physical structures and tillage methods that retain crop residues on the 


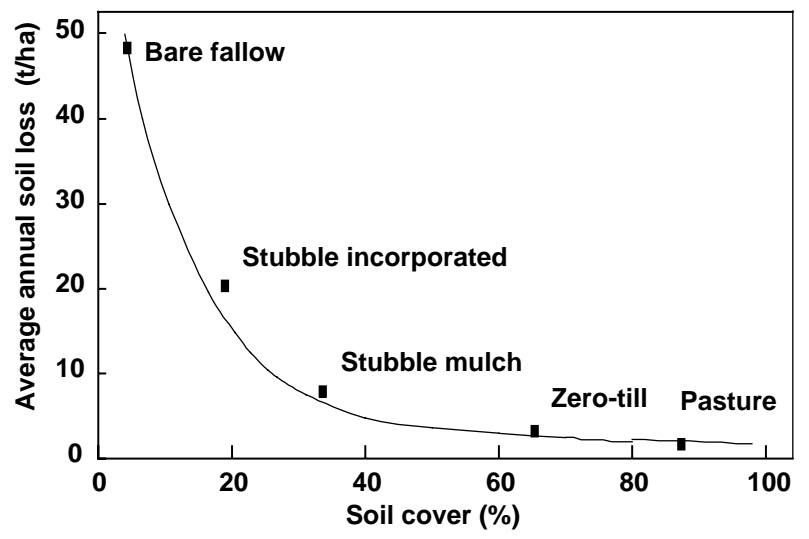

Figure 1. Annual average soil loss $v$. cover derived from contour catchments on the eastern Darling Downs (7\% slope, $60 \mathrm{~m}$ slope length, 1978-92). The shape of this response is similar in many studies. (Modified from Freebairn and Wockner 1986.)

soil surface have been used to control soil erosion. Technically, the issues are well described and solutions are understood. Typically, erosion is manifest as rills, gullies and eroding waterways after major erosive storms. To measure changes in erosion rates - a notoriously sporadic process (Freebairn and Wockner 1986) - or water turbidity, is technically difficult and has a high chance of not yielding any significant signal of performance over a period of years or even decades. This is particularly relevant in the current RD\&E environment where initiation of long-term monitoring programs is not attractive to funders or scientists. Alternatively, we can use descriptive relationships derived from detailed studies which link erosion risk to management.

For example, a relationship between soil cover and erosion is a robust indicator of erosion risk (Fig. 1). Soil cover is an indicator that is easily measurable within good accuracy at the paddock level and requires no specialist equipment other than an informed eye. Further development in remote sensing may also be practical in providing soil cover estimates at the farm, catchment and regional scale. The use of simulated rain has proven effective in providing this type of information at the paddock scale with landholders (Hamilton 1995; King 1997), both at a research level and as a learning tool.

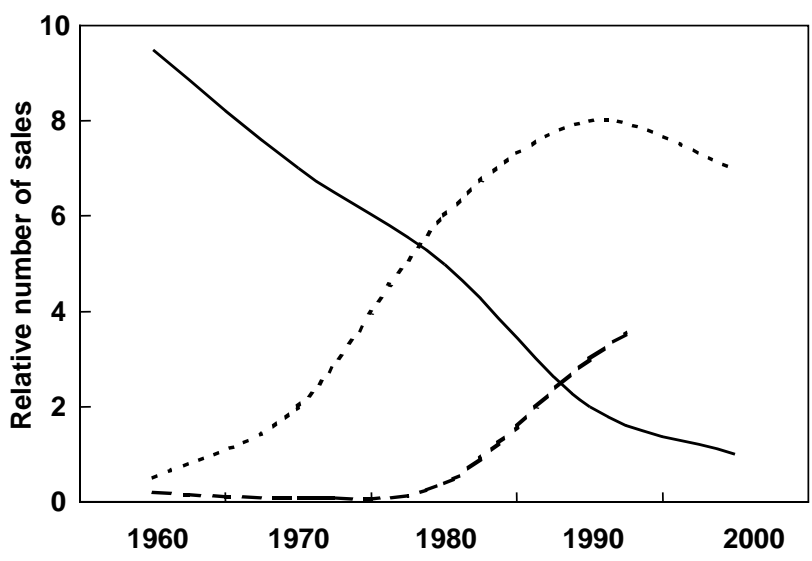

Figure 2. Qualitative trends in machinery sales in southern Queensland, 1960-2000. Data were collected from a range of machinery manufacturers, farmers and scientists involved in conservation tillage research and extension. - Disc ploughs, - - - chisel ploughs, - - - no-till planters.

An alternative index of erosion risk could be awareness and use of more environmentally conservative tillage practices (e.g. stubble retention) which may be reflected in machinery sales (Fig. 2). Data in Figure 2 were obtained by surveying a range of machinery sales firms, and was cross-checked with a written survey of 30 land managers representing dryland cropping in southern Queensland. Disc ploughs are characterised by their ability to bury crop residues, and were used to quickly create a 'clean' fallow which is now known to be highly vulnerable to erosion. Their use has been replaced by chisel ploughs, herbicides and planters capable of planting into high levels of crop residues. Indices of tillage practice or machinery use may be more readily amalgamated at the regional, state or national scale. Changes in management can then be easily linked to physical response relationships to provide estimates of change in environmental indicators such as erosion rates and water quality.

Table 1 illustrates soil cover conditions that result from a range of crop/soil management practices. Changes in tillage implement use shown in Figure 2 link practice data from Table 1 to the cover-soil loss relationship shown in Figure 1. Figure 3 shows a schematic of how these data sources are

Table 1. Expected soil cover during the critical summer period (October-March) for a range of crop and tillage management options

\begin{tabular}{lc}
\hline Predominant crop-tillage management & Typical soil cover (\%) \\
\hline Grazed oats & $<5$ \\
Wheat-fallow, stubble burnt or incorporated (disc plough) & $<5$ \\
Wheat-fallow, stubble retained (sweep plough) & $30-50$ \\
Wheat-fallow, no-till (herbicide weed control) & $>60$ \\
Sorghum, stubble retained & $>60$ \\
Sunflower & $<30$ \\
Pasture, well managed & $>80$ \\
\hline
\end{tabular}




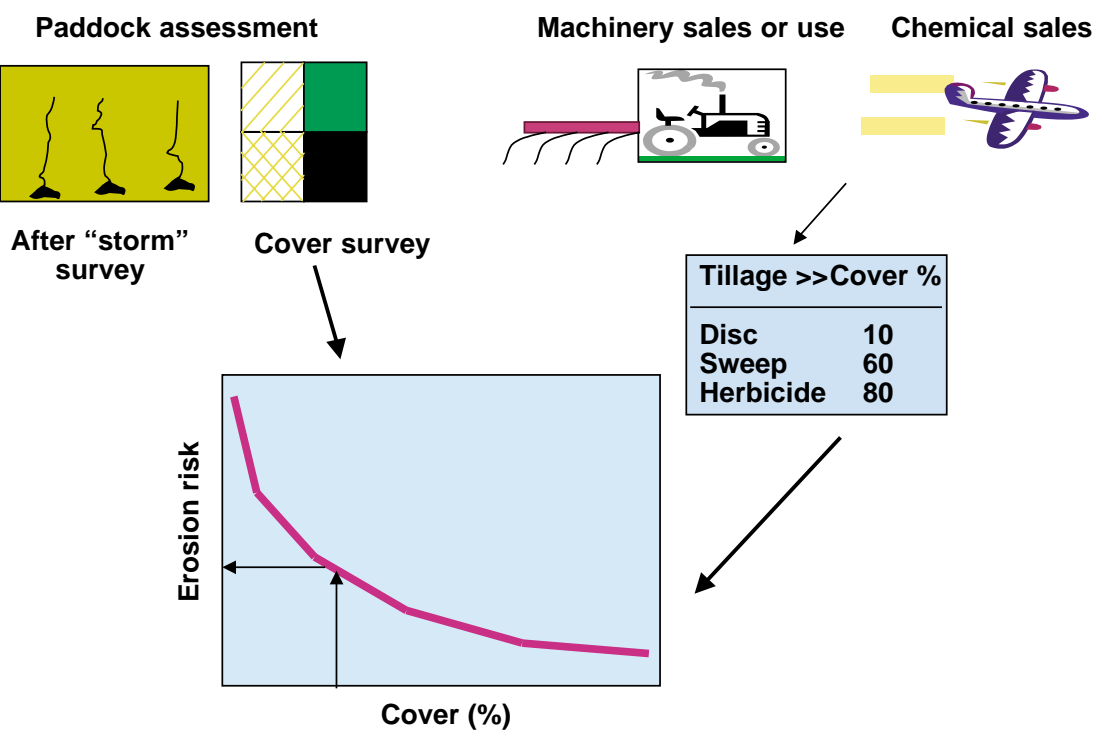

Figure 3. Schematic for linking field observation, machinery and herbicide sales to erosion risk assessment. Paddock assessment refers to surveying erosion after events (shown as rills and silt deposits in contour channels), and measuring soil cover by eye, with cover standards.

linked. An advantage of using a range of indicators, all focusing on erosion in this case, is that there are good links between practice and environmental risk, and there are a number of ways of collecting and using data. More importantly, land managers can easily compare current and proposed practices at a level which is meaningful to them, i.e. there is no need for any complex transformations or models to provide explanations.

It is useful to consider these alternative indices of erosion hazard in terms of development, measurement and application. The relationship between soil cover and erosion, while having commonality for a range of soils and environments, was the product of 10 years of research. Also, other studies in a range of environments have found similar relationships between soil erosion and soil cover, highlighting the robustness of this relationship.

To measure erosion rates directly requires equipment and support over a long period (Freebairn and Wockner 1986). In contrast, soil cover used as an indicator is simple and only requires going into the field and making observations by eye, possibly with the assistance of cover standards (Molloy and Moran 1991). For this paper, machinery sales figures were collected from a range of expert opinions within a few days, and in this case represent trends over a region. Official figures were not available from the machinery industry. It is unlikely that a more technical approach could provide a robust estimate of changes in erosion hazard through time.

\section{Salinity hazard}

Dryland salinity is driven by changes in the water balance when land use changes result in an increase in water loss below the root zone. Figure 4 shows the elements of the water balance. Changes in any 1 element can create changes in any other element. Typically, moving from perennial to annual species results in either increased runoff and/or drainage. When this increased drainage creates a rising watertable, it can mobilise salt in the soil, or bring saline ground water to the surface. Currently, the broad assessment of salinity risk in the northern cereal belt is still unclear. This uncertainty is due to the relatively small proportion of currently affected land, and an assumption that hydrologic processes in environments with summer dominant rainfall will not lead to the same level of salinisation as southern Australia. This is based on the fact that evaporation potential

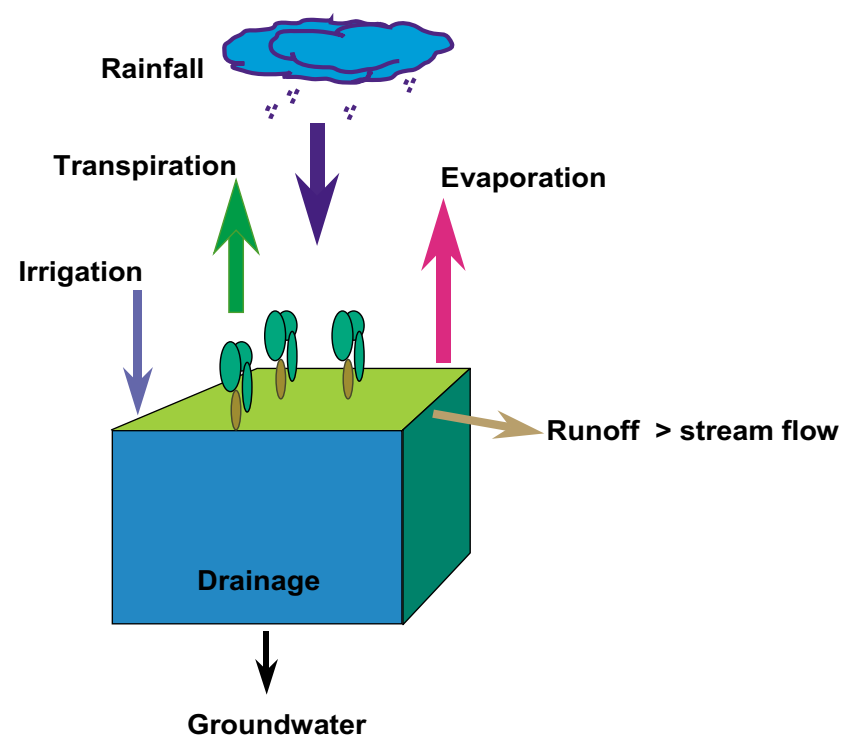

Figure 4. Schematic representation of a water balance model. 
in all months is $2-3$ times mean monthly rainfall. Since the symptoms are currently not so 'visible', however, questions raised include: 'Do we have a potential problem?' and if so, 'Can it be measured? How can it be managed? Are there any simple indicators?'

While we have had a capability to model all elements of the water balance for some time, there has been little stimulus (relative to southern states in the last decade) to look at drainage or leakiness of different land uses. It was thought that heavy clay soils in the north did not leak water below the root zone! In order to provide some guidance to understanding the issue, we have used a simple water balance model derived indicator that uses cropping frequency as an indicator of leakiness (Fig. 5). This relationship is supported by building understanding within the farming community on how the water balance functions, and what factors may influence the relative movement of water between processes of transpiration by vegetation, evaporation, runoff and drainage. Another model that uses soil chloride profiles to infer drainage has also been used to rapidly assess drainage behaviour of different land uses and soil types (Department of Natural Resources 1997). While such models are not suited to use by farmers, the exploration of salt distribution in their soils in an action learning setting can be a very powerful learning exercise in understanding soil water behaviour, and implications of land use changes.

Two key concepts that have been useful to explore drainage risk with land managers are: depth of root exploration (or water extraction) and temporal water use

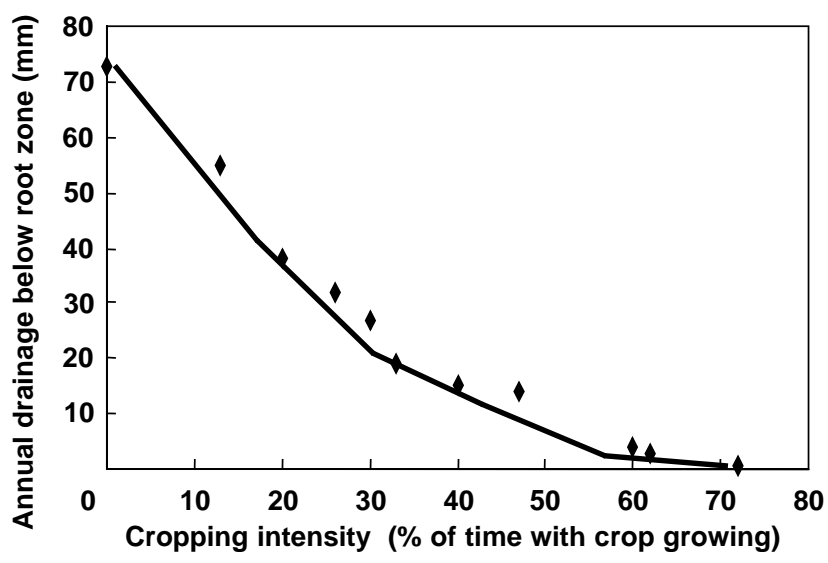

Figure 5. Estimated drainage below the root zone for a range of cropping intensities, based on cropping system model on a Black Earth at Gunnedah (after Abbs and Littleboy, 1998).

patterns of different species. Figure 6 demonstrates conceptually how 2 different land uses may affect water balance, using hypothetical rooting depth and water use patterns. Note that the water use pattern of a perennial more closely matches rainfall, while a winter crop has a period of fallow to store water; followed by a crop phase where water use may be greater than rainfall. Fallowing is an important tactic for growing winter crops reliably and profitably.

Drainage is challenging to quantify experimentally, and due to low farmer and scientist awareness, has not been studied as extensively as more obvious degradation

\section{Natural vegetation}

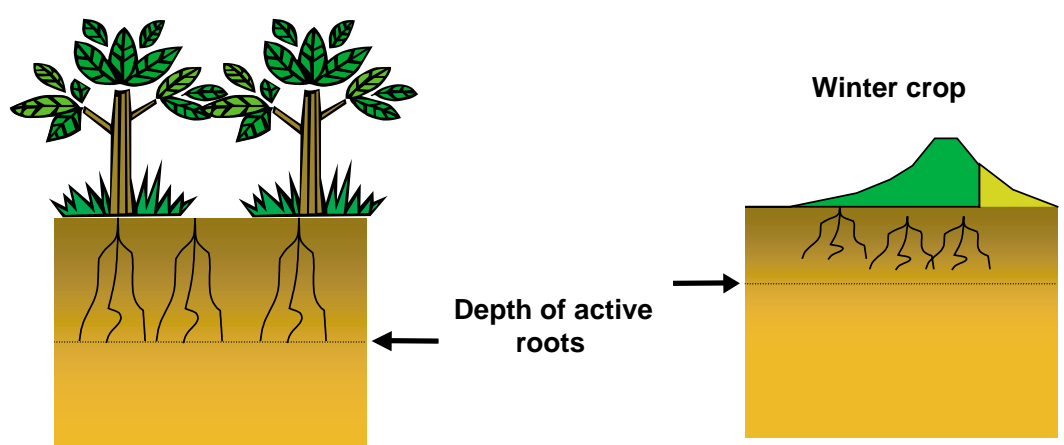

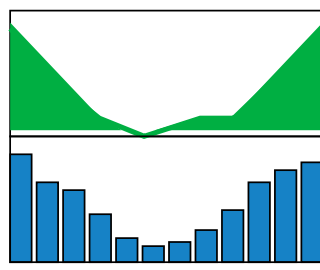

Jan.

Dec.
Water use through the year

Rainfall

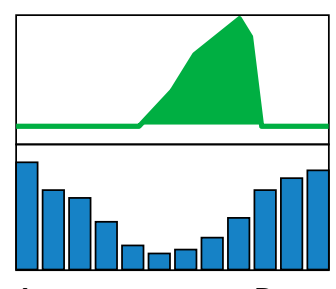

Dec.

Figure 6. A diagrammatic representation of hypothetical rainfall and water use patterns under natural vegetation (trees, shrubs and perennial grasses, note deeper water extraction) and a winter crop-summer fallow. 
processes such as accelerated runoff and erosion. In an attempt to reduce the time to provide some guidance and improved understanding to farmers before results are available from a rigorous research phase, a cropping system model can be used to explore possible drainage rates for a range of cropping scenarios (Fig. 6). Initially, the absolute values should not be important, rather the principles of why water balance components may change, leading to awareness and understanding is more important. As more detailed scientific understanding becomes available, an environment of increased awareness will lead to greater credibility and ability to respond to problems.

This proposed approach has similar simplicity to the cover-erosion relationship presented in Figure 1. Field observations of rooting depth and proportion of time that the land is in crop are straightforward and the concepts are relatively transparent. Ridley et al. (2003) use the concept of perenniality in a similar manner. Such information can stimulate learning groups to explore the depth and quality of groundwater if their systems appear to be more leaky than natural vegetation. Basic resource information on groundwater systems, soil and water salinity, and land use changes are still required to obtain an understanding of the spatial and temporal nature of salinisation at a regional scale.

It should be noted that the idea of planting more crops or perennials provides only one option in the northern cereal belt of Australia. This would be a fairly narrow view of salinity intervention. A mix of strategies that include changes in land use, engineering practices, changes in water allocations and productive use of saline land may be more successful than a single solution.

\section{Nutrient balance}

Nutrient decline of soils, and subsequent loss of production or product quality is well recognised across Australia (Hamblin and Kyneur 1993). Whether this represents an irreversible loss is debatable, but it is generally regarded as an erosion of physical capital. Management practices associated with nutrient management include soil testing, fertiliser application and inclusion of legumes in rotations.

In the northern cereal region, export of nutrient in grain, meat and fibre is greater than inputs from fertiliser, with only $27 \%$ of nitrogen and phosphorus being replaced in the Condamine-Balonne-Calgoa catchments (Pulsford 1993). While an audit of fertiliser use would conclude that crop production is still in an exploitive phase, one issue is how to gauge improvement in either management or soil and crop status. One approach is to explore how management can be improved through awareness and skills development.

Two concepts have been used as management aids in nutrition: nutrient balance and balancing crop needs. Nutrient budgeting uses the relationship:

Change in nutrient pool $=$ Nutrients added - Nutrient lost
Nutrient loss is due to erosion, leaching and export of nutrient in products leaving the paddock, farm or catchment. The second concept, balancing crop needs, requires the calculation:

$$
\begin{aligned}
\text { Amount needed } & =\text { what the next crop may require } \\
& - \text { amount in soil }
\end{aligned}
$$

What the next crop may require is estimated for a specified yield and protein. Soil status is based on a soil test. The first relationship is used at a more strategic or planning level while the latter is typically a tactical response (Lawrence et al. 2000).

Lawrence et al. (2000) showed that after an action learning exercise involving budgeting for nitrogen crop requirements based on soil tests, farmers' awareness and practice changed. They presented a case study where a learning goal was achieved, and resulted in improved practice - sometimes more fertiliser was required and used, although other cases indicated an abundance of nitrogen, and rates were decreased. It is our proposition that it is more useful to gauge (and ideally be involved in) the level of purposeful learning and planning. The act of considering nutrient budgets is in itself an indicator of sustainability.

Another approach would be to measure or estimate soil organic carbon as an index of soil quality and nutrient supply. Ideally, if soil organic carbon status measurement were to become a standard practice as part of property description for sale, then a new market signal reflecting soil management could be established. This use of soil organic matter as a land descriptor could become a powerful indicator of system status and property value. The approach will be most useful, however, when there are few 'other' signals that influence land value (e.g. distance to grain terminal, local town). In addition, the measurement of soil organic matter trends on a regional scale may not yield any useful signal unless very intensive and long-term measurements were made (e.g. Dalal and Mayer 1986).

\section{Water-use efficiency - an index for gauging production performance}

Production and profit are generally high on the list of indicators of how well a farm or system is performing. Pannell (2003) makes the point that farmers evaluate yield and profit as a normal part of business. One of the problems in using raw production or profit is that production is highly dependent on rainfall. Water-use efficiency (WUE) is an index that describes the efficiency with which water is converted to a product (fibre, grain), and is typically expressed as $\mathrm{kg}$ of product per mm of water supply. WUE provides a means of normalising this variation. The concept was developed in South Australia (French and Shultz 1984), and is adjusted here to account for the greater dependence of crops on stored water in the northern cereal region (Fig. 7). This simple model assumes that water used by a crop is 


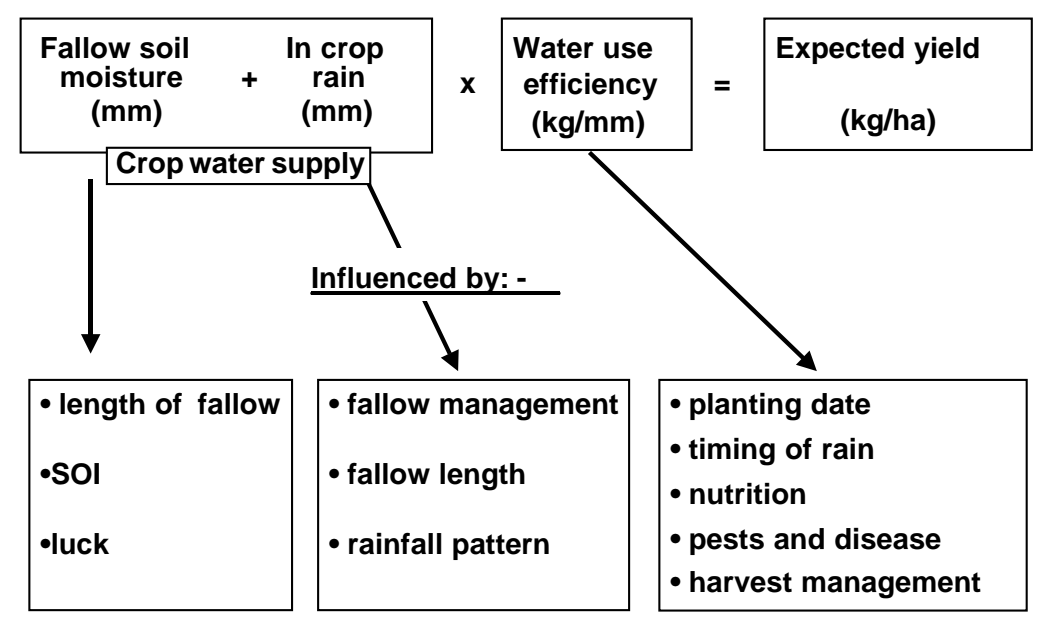

Figure 7. Schematic of the water-use efficiency (WUE) model, showing factors that influence each element of the model.

converted to yield in a predictable and linear manner, and that limiting factors will reduce this efficiency. Of course it is well recognised that timing of rain also influences yield. The simplicity of the model is a strength in terms of explanatory power and ease of use, but is also a basis for its criticism, particularly by those who have more sophisticated tools. It should be noted that concept is more suited to water limiting environments.

In applying the model, ideally we know starting soil water, and in-crop losses due to evaporation and runoff. However, estimates of these losses are not generally available. In practical application, starting soil water is estimated simply as $20 \%$ of fallow rain, and all in-crop rain is assumed to be available to the crop. These assumptions are not critical to the process, although they should be kept constant for any comparative exercise. Estimates of WUE use rainfall records and crop yield, allowing farmers to gauge how effective they have been in using a key resource water. A farmer or consultant can review a crop's performance based on regional expectations of efficiency. For example, yields presented in Figure 8 can be reviewed to explore why some crops fall well below the arbitrary target WUE of, in this case, $10 \mathrm{~kg} / \mathrm{ha} . \mathrm{mm}$. A comparison of WUE for different paddocks, farms, and treatments provides a simple framework for exploring responses, while taking away some of the variation attributed to rainfall.

Limitations in using WUE are many. WUE varies due to timing of rain during the season, temperature and other seasonal conditions, yet it is still effective in flagging whether other unspecified issues are seriously limiting production, especially when comparisons are grown under similar conditions. For example, Ridge et al. (1996) showed that variation in nitrogen accumulation in wheat at flowering changed WUE from 3.7 to $10.3 \mathrm{~kg} / \mathrm{mm}$. The strength of this model is that it is simple, robust in environments which are strongly water limited, and amendable to simple 'what if' calculations such as 'what if a management practice enabled an extra $20 \mathrm{~mm}$ to be stored in the fallow; what is the likely response?'. For crop rotations with sequences that cover several seasons or years, WUE needs to be considered on an annual or longer basis.

\section{Financial performance}

In addition to the biophysically based indicators above, a variety of indicators that represent financial performance have been used (Rendell et al. 1996). Unlike many of the biophysical indicators, these tend to have more general application (i.e. less context dependent), speaking the language of business orientated farmers and their financiers. Three indicators commonly used are: (i) \$WUE [financial and biophysical efficiency]; (ii) disposable farm income/family [financial viability]; (iii) on-farm:off-farm asset ratio [financial stability].

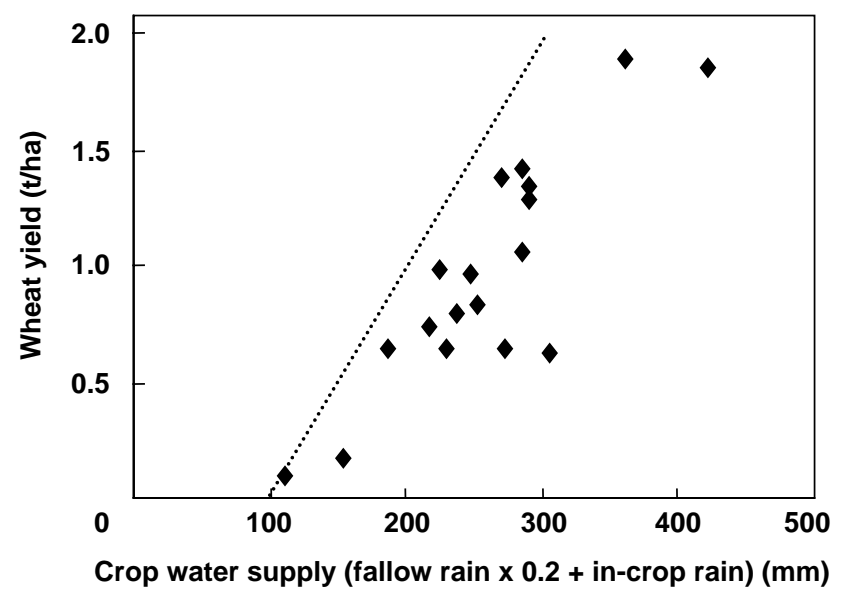

Figure 8. A plot of crop water supply $(0.2 \times$ fallow rain + in-crop rain) for 18 years of shire yields (1975-92) in the Walgett shire, New South Wales. The dotted line represents $10 \mathrm{~kg} / \mathrm{mm}$ with a $100 \mathrm{~mm}$ water supply threshold. 
An addition to the WUE concept, \$/WUE, is the profit achieved for each mm of water supply ( $\$ /$ ha.mm). Crop yield and quality are converted to dollars using standardised prices for commodities. At a farm scale, \$WUE has been shown to be an effective approach to gauge production efficiency (Ridge et al. 1996). The question remains as to whether such an approach is achievable at a shire or regional scale. Again, like WUE, \$WUE is prone to considerable variation resulting from factors other than management, including price fluctuation, but \$WUE is closely related to business performance. The use of production-management indicators such as WUE and \$WUE reflect an awareness of benchmarking as a management tool. The use of these tools is an indicator of sustainability in its own right. Recent innovations in broadacre grain systems have shown rapid uptake of such approaches (e.g. FAST and TOPCROP groups). At the regional and state level the derivation of \$WUE type indicators may prove useful at a policy level where awareness of the relative value of water may be a potent force in water allocation decisions.

Pannell (2003) comments on the common practice of including standard socioeconomic variables in lists of suggested sustainability indicators. He suggests that including these variables (that are routinely collected by a range of agencies) appears 'to be mainly a needless distraction from the core issues... A better role in the process for the economics discipline would be to evaluate the economic viability of available resource management practices, and to assist in assessing the economic benefits of monitoring.' We acknowledge that there will always be debate amongst economists (and others) as to what are the most appropriate indices to use (or whether they should be used at all) and recommend that the real issue is that a purposeful and contextual approach to financial analysis is undertaken.

\section{What have we recently begun to monitor?}

If we take a contemporary systemic view of farming systems, we propose that the traditional focus of monitoring (on biophysical and financial parameters) should also be accompanied with indicators representing human activity. This emphasises a systems approach that involves exploring the complexity of interactions within the 'hard' and 'soft' systems following suggestions by Röling and Jiggins (1998). The 'hard system' can be viewed as the biophysical components that can be measured or modelled using simulation techniques, while the 'soft system' can be viewed as the interactions between the biophysical components, technology and land managers (typically farm families).

We suggest that it is the purposeful focus on both the soft and hard systems in relation to indicator development and use that is one of the main features that distinguishes this paper from the myriad of other papers on sustainability indicators in the resource management domain. It is a field we have been 'dabbling in' for the past 5 years (e.g. King
2000 ) and we believe it has led us to a more holistic view of a farming system with regard to the development of indicators. Below are a number of indicators that represent human activity (rather than biophysical status) that, from our experience, are showing promise in the northern cereal belt. We suggest that they can be placed in 2 main categories: individual and collective empowerment.

Individual empowerment. The first indicators we present as human activity indicators are those that indicate the interaction between an individual farm family or individual farmer and the technical elements of their production system. They are indicators in their own right and are indicators of 'process' rather than state. They represent initiatives to improve RD\&E by improving knowledge and the decision-making capability of individuals and farm families through an empowerment process. For example, the first point below is not the WUE measurement, but rather, the use of WUE as a concept in informing decisions.

(i) The use of WUE and \$WUE as guides to management planning and performance review (system evaluation); (ii) The use of nutrient balance accounting and tactical adjustment in consideration of current soil status, weather and market futures; (iii) Establishing ground cover targets for erosion control [resource management]; (iv) Record keeping to track performance and comprise part of an environmental management system; (v) The use of conservation tillage principles; (vi) Implementing ley pasture phases in cropping systems to preserve soil organic matter; mix of grass and legume-based crops for more balanced nitrogen supply; (vii) Practising crop rotation to minimise pest carryover between crops; (viii) Use of climate forecasting information to optimise inputs and reduce risks; (ix) Use of farm financial indicators to guide whole enterprise planning (e.g. FAST indicators, Rendell et al. 1996) (financial viability); (x) Whole farm analysis carried out to determine key areas for potential improvement (land and water plans developed) (link between production and resource conservation - system perspective).

Collective empowerment. More recently, with the integration of community development into RD\&E agency agendas, another range of indicators that are being explored in the northern cereal belt are those to do with collective empowerment rather than individual empowerment (King 2000). Rubin and Rubin (2001) suggested that collective empowerment comes about as people learn that they share a responsibility for each other and the environment and by doing so, help create social capital, a resource for future community prosperity. It is different to individual empowerment where individuals who feel they can succeed are empowered. Rubin and Rubin (2001) suggested that the aggregate result of individual decisions is that the economy of a small community will be unable to sustain itself. They provided a variety of examples to illustrate this, suggesting that: 'although earning from outside a community may be 
fairly strong, it will lack the interdependencies and linkages that would transform this outside income into additional income and jobs. The solution to this problem does not lie particularly in attempts to find additional export markets or to attract additional firms with an export orientation. These methods only promote more of what was already present in abundance - a focus on individual action as a method of generating development. Individual action is unlikely to solve the problem, since it was individual action that was responsible for the problem in the first place.'

Although earlier indicators have been successful in monitoring individual empowerment, they have done little for what Rubin and Rubin (2001) term 'collective empowerment' except for the benefits associated with the product intervention mechanism being a group environment. As described by Fairbairn et al. (1991):

'The answer to the problem of community development lies not in promoting more individual action or in enticing outside businesses, but in encouraging the community to take action as a group and to find solutions from within...the problem with [individual empowerment] programs is that they create competition among communities.'

Some of the indicators that we have used in the northern cereal belt include: (i) the number of community capacity building initiatives; (ii) community groups carrying out catchment planning and implementing their plans; (iii) the establishment and membership of production and conservation learning groups within the community; (iv) the development of learning tools for farmer and community groups; (v) the use of benchmarks by farmer or community groups to indicate resource and production efficiency; (vi) methodologies developed for and by farmer groups to carry out 'legitimate' on-farm research and monitoring; (vii) the development of formal and informal networks to address common issues and concerns; (viii) perceived community interdependence and responsibility; (ix) the use of methodologies specifically designed for participatory learning and collective action.

The above indicators are not a comprehensive list; however, they do represent an emerging interest and emphasis on previously neglected human activity indicators. Below, we take the broad area of participatory learning and explore it in more detail.

\section{Participatory learning}

The broad areas mentioned in the previous section of this paper are somewhat technical through the eyes of the social scientist (i.e. erosion hazard, salinity hazard, etc.). Here, we offer the concept of participatory learning, to illustrate an indicator that represents the 'soft' system. In general, this type of indicator represents changes in approach by government agencies. They have become more concerned with identifying and measuring success of programs and activities dealing with improved decision making by communities in resource management, rather than the adoption of specific agricultural practices by individuals.

Some of the questions often asked about learning in general are: How do we best evaluate learning? What do we measure? When does learning become action learning, action research or reflective learning? How do we continually improve on the way we facilitate learning approaches? Learning and improved decision making skills seem vague as a criteria and so appear more difficult to measure than past criteria such as the adoption of a technology. However, qualitative evaluation methods offer a way around this difficulty. They can tease out the less tangible subtle influences on behaviour and show promise over traditional quantitative methods in helping to better understand complex issues. When the word 'participatory' is added to the concept of learning, even more questions arise.

In a study by King et al. (2001) farmers from a conservation cropping group identify a variety of indicators that measured whether or not their group was learning. These included the generation of discussion, asking of questions and open communication among people in the group. In addition to the learning that occurred through discussion, most group members believed that if they were trying new things in farm management they were obviously learning (i.e. the ability to consciously test ideas). The farmers in the study found it easy to identify the benefits and pitfalls of why some activities or events were more successful than others in terms of participatory learning. The following example illustrates 2 comments from the study.

'You want something not too technical ... and its better if it's short and intense ... not a drawn out thing. It has to have a simple concept ... but with in-depth stuff behind it ... so you can just stand there and grasp the simple concept ... or you can go more detailed if you want.'

'A convivial atmosphere to learning is good. Members are now trying to help each other learn. We ask more questions now. There's an inherent matching of each other now to information, etc. We are a lot more committed to doing things as a group.' (example responses in relation to 'learning indicators' from 'Convergent Interviews'; King et al. 2001).

Developing indicators around an 'action learning' process (an active process by the learner where the learner 'learns from an experience and then applies critical reflective observation to determine the usefulness to their situation prior to planning their next action or learning experiences') has also shown potential. King et al. (2001) illustrates how understanding the principles of different learning processes can aid in developing indicators to evaluate learning activities. For example, a useful action learning tool may be one that enhances the action learning processes by: (i) enabling discussion; (ii) allowing for repetitive cycles for continual evaluation and improvement; (iii) relating to the participants' context; (iv) being flexible and adaptable to participants' needs. 
Indicators can also be developed using the principles of adult learning. In order to initiate or enhance learning to bring about change in a situation, whether it be a change in cognitive or behavioural situations, it is important to understand the factors that influence the learning process. These can then be used to develop more effective (and efficient) ways of facilitation that are suited to the learner.

In the study by King et al. (2001), the use of a rainfall simulator (RFS) as a participatory action learning tool is used to illustrate this. In their scenario, the RFS can be seen as the tool and the RFS field day as the process. Indicators can be developed by a facilitator during the design phase that aid in facilitation and evaluation. For example, a facilitator may decide to design a field day based on the principles of adult learning and participatory action research. If a simplified model of action research is used such as 'plan, act, observe and reflect', it is also possible to identify and develop indicators for each of these stages, based on adult learning and participatory action research. A facilitator might establish a set of indicators based around questions such as:

In the planning phase. (i) Have we related the activity to participants' experience? (ii) Have participants been involved in the design and implementation of experiments? (iii) Who is participating and who is not? (What are the implications?)

In the action phase. (i) Are participants aware of what they are trying to measure and why? (ii) Are participants sharing ideas and communicating during the RFS run? (iii) Who is participating and who is not? (What are the implications?)

In the observation phase. (i) Are processes transparent? (ii) Are participants collecting data and how are they doing it? (iii) Are participants aware of the assumptions behind collecting 'accurate' data? (iv) Who is participating and who is not? (What are the implications?); (v) Was there a feeling of trust generated?

In the reflection phase. (i) Are different observations and interpretations being acknowledged? (ii) Have we put the generalisations and concepts that have been drawn into a future context? (iii) Have we allowed for participants to form their own generalisations and concepts? (iv) Do participants value each other's ideas and knowledge? (v) Have 'why' questions been asked to aid in double loop learning?

When designing, facilitating and evaluating a RFS day, questions (relating to particular indicators) can be used to indicate effectiveness of a learning process and how it might be improved. An evaluation at the end of the day may also be useful, especially if participants are asked 'What have you learnt?' as opposed to 'Did you learn?' where the usual reply is 'yes, we've learnt!' The example above does not attempt to provide a full set of questions, but rather to illustrate the usefulness of articulating processes to help establish useful indicators and questions about participatory learning. These questions provide prompts for improving future activities.

This section has provided examples of indicators for a variety of broad issues (e.g. erosion hazard, salinity hazard, participatory learning). The main conclusion that we draw from these examples is that there is much complexity in indicator application. Indicators are most often context, purpose and scale dependent. To proceed from this, in the next section some frequently asked questions about indicator development and application are addressed.

\section{Indicator development and application — frequently asked questions}

We now put forward some general ideas on indicators in light of our experiences in working in the 'indicator industry'. In doing this, we address a number of questions we have commonly been asked about indicators and indicator development.

\section{Why have indicators?}

In the introduction, we listed the public motivators for developing indicators. To follow our argument that indicators with a 'soft' system or behaviour focus have an important role to play in improved management of production and natural resource systems, we suggest that most improvement systems benefit from their own set of benchmarks to guide performance. This 'performance' may be technical, managerial or learning based. Since our production system is based in a highly variable climate (hard to have reliable and simple physical state indicators), and is managed by people (multiple perspectives), we believe we need a range of indicators to help us guide and measure progress. Our main thesis is that 'soft' system indicators (e.g. behaviour) are just as important (if not more important) to measure as 'hard' system indicators (e.g. biophysical status). We argue that indicators need to be sensitive to the complex environment in which they are to be applied, for example, multiple perspectives with ongoing changes in understanding, attitude and practice, within the timeframe of projects and activities. In addition, rapid feedback is required if we are to optimise any activity rather than wait decades for a physical signal such as rising saline watertables. Although we promote the use of indicators for improved management of these systems, we also believe that indicators are not always the answer or appropriate for some situations.

\section{Who are we developing indicators for?}

The question arises; are we facilitating change or are we directing it? In the current policy environment (e.g. State of Environment reporting), it appears that government is dictating that we have indicators, and that there be some form of uniformity in approach, and that these indicators will assist policy in directing support or control measures. Alternatively, we can engage client groups to develop common language and common approaches for their own 
contexts, as part of a refinement and improvement cycle, where the application of indicators has tangible benefit in the short as well as long term.

Changes in agendas, at the farm, industry, regional or international level can dictate that indicators be used in different ways. For example, the emergence of greenhouse gases as an issue that may influence the way we manage ecosystems. In this case the role of soil organic matter as a carbon store might take over from its current role as a soil physical and chemical fertility indicator.

\section{How should indicators be developed?}

Development of a purposeful process of continual refinement (through questioning and learning), which brings together (and explores the interactions between) production, resource economics and people, is central to the philosophy of effective indicators of performance. A challenge is to develop a framework or process where local and regional group indicators can be aggregated up to levels required for policy analysis at state and national levels. The most important contextual issue is that land managers or community are involved in, and benefit from, any indicator development. A key to achieving this is flexibility, allowing indicators and their application to change as context changes over time.

History tells us of many technologies that have failed because end users have been excluded from their development. Ideally, we suggest that indicators be developed in partnership with land managers, and whoever else is seeking information on performance trends. Realistically, indicators are developed by all players, sometimes in isolation, and carry the values and emphases of each group. The crucial issue is whether the indicator(s) have value to the players in terms of supporting their management decisions, whether these be in an on-farm, industry or national context.

\section{Should indicators aim to be general or specific?}

The value of an indicator is often determined by the context with which it is being used. Policy level indicators typically need to be general since they are aiming at broad community level issues. Land managers need specific indicators that can reflect changes that they may make in practice (whether cognitive or physical changes). These indicators have to be used as guides for better management (or at least initially to flag problems). Stoneham et al. (2003) discuss the concepts of broad and narrow sustainability in practice, acknowledging the importance of both of these approaches to social, economic and environmental sustainability. They suggest that depending on what society's objectives are, there are legitimate applications of either broad or narrow sustainability. That is, different approaches (as with indicators) are dependent on purpose and context. In addition, most issues require several indicators to describe performance, especially when we are dealing with natural production systems where we are aiming to optimise physical, social and economic goals.

\section{Can the one indicator be used at different levels of scale?}

The sample indicators illustrated so far can be aggregated at the regional level, but there are few good reasons why an indicator should be aggregated up or across regions. As scale changes, the audience and function (or as seen above, the purpose and context) of an indicator may also change. Any 1 indicator may have a different response shape depending on the land use system. For example, more herbicide use could be considered positive for erosion control, but negative for herbicide resistance and water quality. The search for universal indicators ignores the physical and social differences across scale and geography. As Abbot and Guijt (1998) explain; 'It cannot be stressed enough how important it is to know exactly who the end user(s) of the information will be and how the information is to reach them. This determines the entire framework for the methodology: the indicators, the methods, the timing, the reporting and analysis style, the costs, etc... few participatory monitoring approaches invest sufficient time in the planning stages, identifying and clarifying the end users and uses. Much energy is spent refining monitoring methods and developing sophisticated techniques, without thinking about the translation of the data into practical application.'

\section{Are indicators developed by farmers rigorous enough?}

Scientific method generally dictates that scientists have to put numbers to variables. This often requires protocols that set out quality control and repeatability criteria. For example, measurements of soil organic carbon require specialised procedures, often in accredited laboratories, even though spatial variability will require many samples to be analysed before confidence can be placed on the 'accurate' measurement. We have witnessed a farmer showing his neighbours colour photos of water running off his farm from 2 storms, where the land had been managed differently. One showed muddy water leaving a bare fallow paddock, the other clean water leaving his strip crop layout. There was no doubt in the farmer audience response that what was being shown (water colour or turbidity) was valid, and no doubt the demonstration had more impact than an accurately measured 'sediment concentration' in units of $\mathrm{kg} / \mathrm{L}$.

It appears that scientists often feel that farmer developed indicators may be less valid then theirs. Our experience is that we have seen both farmers and scientists regarding each other's assumptions and methods with scepticism. There appears no good reason why farmers' observations and deductions would be any less rigorous than scientists, especially given that farmers are in a position to have rich and continuous observations as their primary data. Our view is that each audience has its own set of standards and their 
own perceptions about what actually represents 'rigorous'. For example, in the eyes of a social scientist, a biophysical interpretation may be seen as lacking rigour because of poor contextualisation. It seems arrogant to impose different standards on each other or insist that one approach is elite. Accommodation of alternate views is the essence.

\section{How can indicators address short-term and long-term considerations?}

This question goes to the heart of the concept of 'sustainability'. What is sustainable? King (1998) illustrate the myriad of ways in which the sustainability concept is approached. Agricultural researchers have been 'seen to act as if sustainability is either goal-prescribing (meeting certain goals) or system-describing (focusing on fixed properties or levels) concepts' (Cox et al. 1997). These goal-prescribing and system-describing approaches are based on 2 main assumptions. First, it is assumed that individuals or groups of individuals share a common meaning about sustainability, and second, the systems they are working with are static or fixed in nature.

It has been suggested however, that meanings of sustainability emerge from within the human communication environment and are indeterminate in nature (Penman 1994) and precise definitions are impossible (Pretty 1995). That is, the meaning of sustainability is constantly changing in different ways for different people in different contexts and hence different realities or perceptions about sustainability will inevitably emerge. Based on this indeterminate perspective of sustainability, an alternative approach has been put forward by Cox et al. (1997) that aims to re-construct sustainability as a process improvement tool in research. The difference with this approach is 2-fold. First, scientists are not constrained by goals, targets or system levels that suggest that the best practice now is the best practice for the future, and second, it allows for the differences in scientists' perceptions about sustainability. This approach asks scientists to examine what might be possible in bringing about better agricultural practices...and how we can continually learn to manage in an open indeterminate world.

King (1998) suggest a more participatory approach, however, involving end users and other actors in the development process. They put forward a co-learning process-analysis approach to sustainability. Our response to this is quite simple; we take the view that sustainability is not a state, and therefore it is not useful to aim for it. The key issue is that we move toward systems that we perceive are more sustainable, and that this is a journey without a finite destination. This is an underlying premise of action research technologies (e.g. participatory learning and action research). Thus, we can use indicators to show change in practice (cognitive or physical), which leads to a change in state (cognitive or physical). It follows then that any indicator that (i) describes a change in practice; (ii) has been developed and tested within a continuous learning process; and (iii) has led to system improvement; may be useful as a long-term indicator. In addition, the process used to develop and test the indicator may also have potential as an indicator itself.

\section{What makes a good indicator?}

An indicator is 'an aid for communicating complex processes, events or trends to a wide audience' (Abbot and Guijt 1998). Walker and Reuter (1996) provided a useful list of 11 criteria for choosing indicators of catchment health. While what we have proposed does not directly conflict with their criteria, we believe they have missed some important elements that are required before indicators are accepted or used. That is, indicators are dependent on system purpose and context, and therefore need to be developed by (or in conjunction with) the end users of the indicator as part of an on-going learning process. A range of indicators needs to be endorsed, recognising that different audiences will have different needs. A mix of approaches is needed at different scales. If indicators are developed solely by an 'eye in the sky' approach they will be regarded as irrelevant at best, and top down imposed and spying at worst.

This paper is based on the premise that for indicators to be of use, they must be developed in conjunction with land managers, and demonstrate change in attitude, practice and consequence. An indicator that is useful in 1 context may not be useful in another context, or perhaps at a different time. We also suggest that in some cases, indicators on the surface appear sensible but may not be capable of detecting a resource response, given extreme temporal and spatial variability. This is not to say we do not support the monitoring of biophysical variables at the farm, landscape or catchment scale. Such indicators can form part of a general awareness framework, and may be used to initiate and prioritise collective action.

The ideas presented acknowledge that indicators which aim to detect changes in a natural resource attribute (e.g. production potential, water quality, soil quality) are likely to be insensitive in a time period of years or even decades. Indicators that reflect changes in behaviour or attitude, and can be translated to likely changes in attributes (e.g. modelling) will be more relevant to individuals and groups which have specific issues. It follows that it is unlikely that there is a set of indicators that have universality across agri-climatic regions. Ideally we need to link indicator activities into existing prototype activities such as TOPCROP, FAST, MEY, the National Land and Water Audit, catchment management and landcare groups.

\section{Indicators for indicators - food for thought}

In this section we endeavour to answer the question 'What indicators do we have to support appropriate indicator 
development?' To address this question, 3 concepts are introduced by way of 3 questions.

\section{Is the indicator developed and applied within a collective learning paradigm?}

We see the role of current indicators and the development of new indicators as most useful when encompassed within a collective learning paradigm. In our experience, 2 major issues affect the usefulness of indicators. First, there is a need for the development of indicators to be occurring across system boundaries. We have seen this happening with Participatory Action Research (PAR) approaches involving farmers and scientists, and involving scientists from different disciplines. What we have learned from these fora is the problems that arise when actors with different perceptions come together for project planning, implementation and evaluation purposes. When this collective approach does not occur, there is little recognition of different players' perspectives, and we end up with separate efforts not acknowledged by other parties.

A participatory learning paradigm has been suggested by some development theorists and practitioners as a way of improving this emerging dilemma (Roling and Jiggins 1994; Kloppenburg 1991). Participatory methods for systems learning and action have been documented (Pretty 1995). This approach is seen as an alternative because it takes into account that people have different perceptions of reality (Davies 1994). We see that from this perspective, people (e.g. farmers and scientists) come together with their existing knowledge (e.g. knowledge of current indicators) and trial it within a collective learning process that takes place in the context in which indicators are to be used. In this regard, current indicators are not a set of 'truths' to be applied, but a set of 'perspectives' brought to the floor to be tested and modified for purpose and context.

A collective learning approach also takes into consideration the differences in meaning of concepts such as sustainability, not only between scientists, but also extension agents and farmers. A learning forum is provided where similar experiences can be reflected on, thus enabling collective discussion and decision making by researchers, extension agents and farmers.

A second issue we see, however, is that PAR, at best, has involved only farmers, researchers and extension agents. It is rare to see participatory learning (not to be confused with information collection workshops) involving, for example, policy makers and farmers and/or scientists, or farmers and agency managers. Figure 9 illustrates where indicator development predominates in relation to participants in the resource management domain.

We see that there are problems in this system and suggest that collective learning needs to occur across all system boundaries (in this case system hierarchies). In this light, we see the relationship demonstrated in Figure 10 as an improvement on the current system in which indicators are being developed. There is also opportunity for indicators to play a role in measuring interplay between the components in the system (and not just the components themselves).

However, the real world is not as simplistic as depicted here, hence we make a distinction between group-based learning and shared learning. Following King (2000), 'Group-based learning and shared learning are different. Shared learning and collective actions mix a range of group, individual and public learning events and processes, braiding them into a complex learning system through participatory processes.' Organisations taking on a shared learning approach will need to know ways of facilitating learning within a complex environment. Perhaps the shaded space (Fig. 10) represents the position of the facilitator!

\section{Is the indicator linked to management practice?}

There has been some debate as to whether farmer knowledge and scientific knowledge can be integrated. Scoones and Thompson (1994) state that 'to remove local knowledge from the web of meaning and influence from which it arose and attempt to fit it into the constrictive framework of western scientific rationality is likely to lead to significant errors in interpretation, assimilation and application'. This means that if RD\&E agents try to learn about the indicators used by farmers, even if learning takes place within a farming system context, the application of these indicators in another context should be done with caution. In this light, we see that the development of indicators should be linked to management practice. Given that scientists live in a different world to farmers, it is very
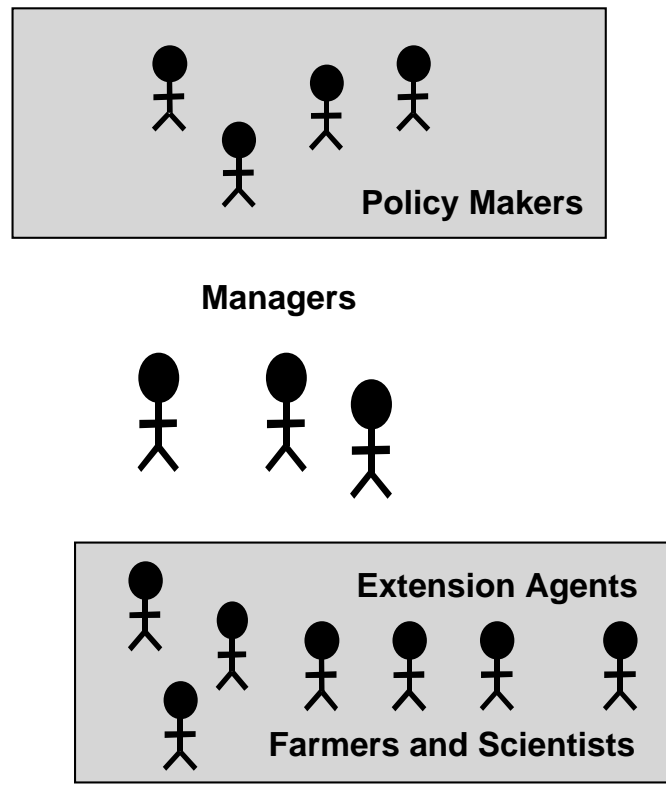

Figure 9. A schematic representation of the relationship between various players in developing indicators. There is no connection between spheres of influence. 


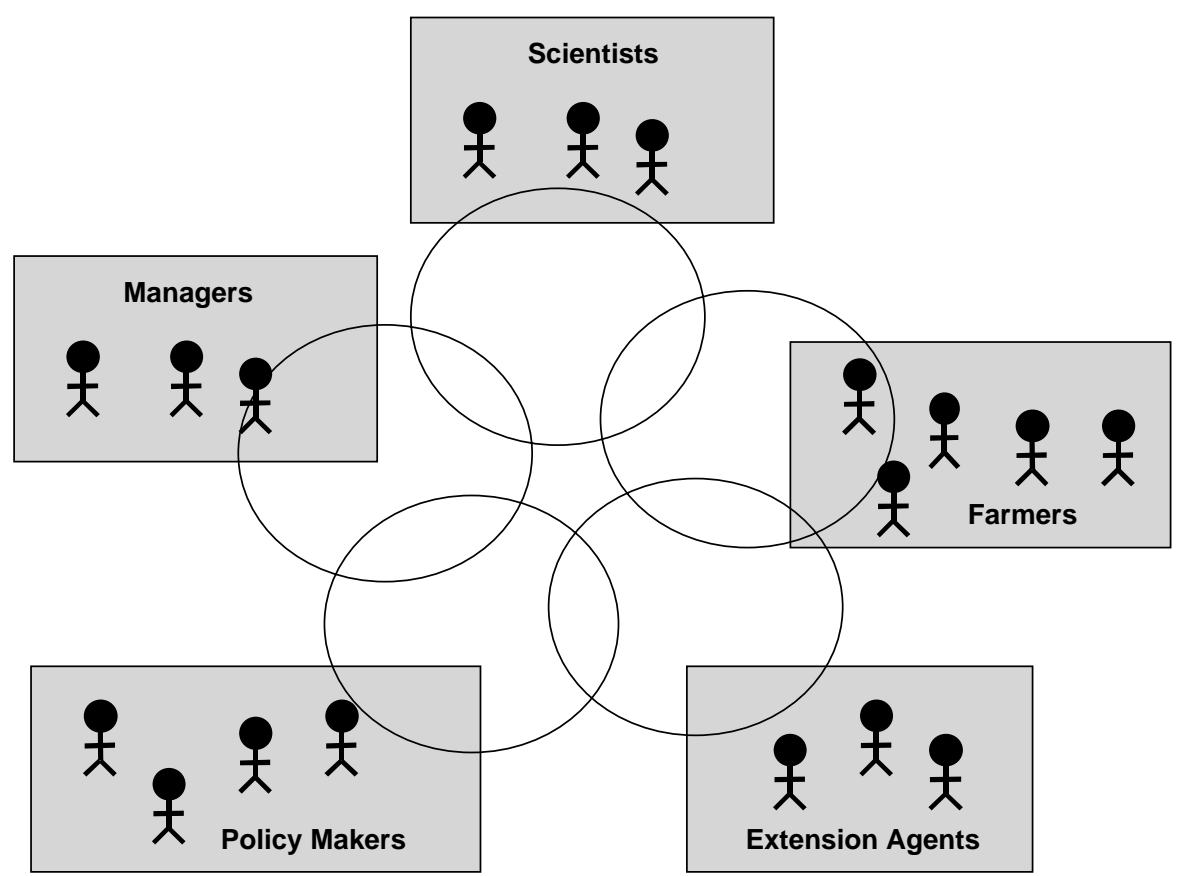

Figure 10. A vision for indicator development, showing relationships between players. Intersections indicate where common issues or approaches are encountered.

difficult for them to embrace a new set of rules and language, and to place their view into a management system. They need to engage farmers, to determine what factors contribute to their decisions, and determine where they have something useful to contribute.

\section{Is the indicator part of a larger 'indicator system'?}

One framework that we have found particularly useful in supporting our approach is the ' 5 capital assets for sustainable development' suggested by Pretty and Ward (1999); natural, social, human, physical and financial capital. Note that biophysical status indicators often align to natural capital only. Each of these assets can be seen as components of the system. This is useful as a checklist for assessing whether a systemic approach is being taken in communities with regard to sustainable development. We have already seen that indicator use and development can occur not just at the component level of a system, but also at the level of interaction between components. A third use of indicators can also be added to this, to measure the emerging properties of a system. Figure 11 illustrates a 'community system' based around the five capital assets for sustainable development suggested by Pretty and Ward (1999) where the following apply.

Natural capital. Refers to nature's goods and services, and comprises food, wood and fibre; water regulation and supply; waste assimilation, decomposition and treatment; nutrient cycling and fixation; soil formation; biological control of pests; climate regulation; wildlife habitats; storm protection and flood control; carbon sequestration; pollination; and recreation and leisure.

Social capital. Relates to the cohesiveness of people in their societies, and comprises relations of trust, reciprocity and exchanges between individuals that lubricate co-operation; the bundles of common rules, norms and sanctions mutually agreed or handed down; and connectedness, networks and groups.

Human capital. Refers to the status of individuals, and comprises the stock of knowledge, health, skills and

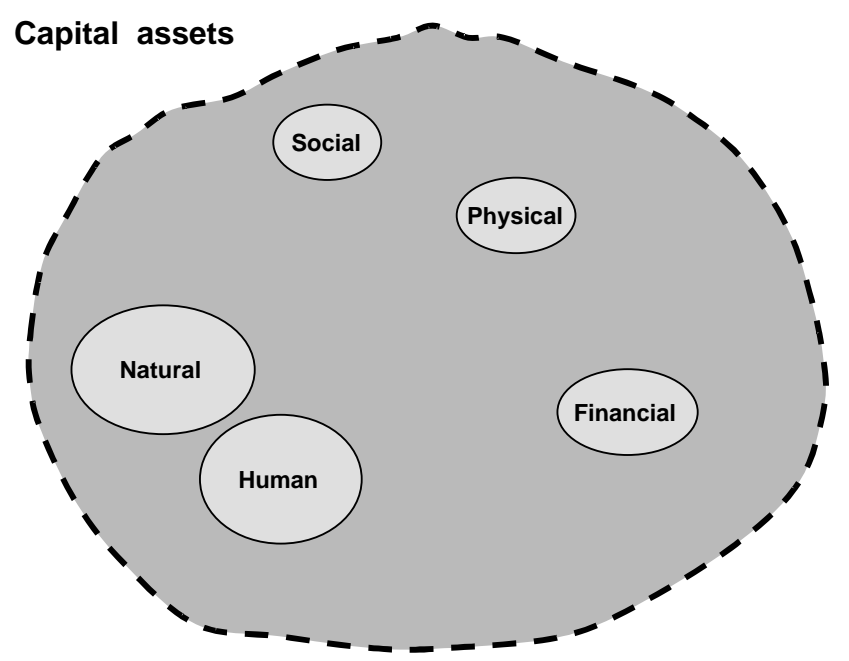

Figure 11. An 'indicator system' illustrating community capital for the northern cereal belt. The connectedness of different forms of capital are reflected in proximity in the diagram. 
nutrition of individuals; their access to services that provide these, such as schools, medical services, adult training; the ways individuals and their knowledge interact with productive technologies; and the leadership quality of individuals.

Physical capital. Is the store of human-made material resources, and comprises buildings (housing, factory plant), market infrastructure, irrigation works, roads and bridges, tools and tractors, communications, and energy and transportation systems.

Financial capital. Refers to financial systems, welfare payments, grants and subsidies.

This can be used as a way of assessing the 'Indicator System' of the northern cereal belt in relation to a community's capital assets (Figure 11). In this diagram, the size of the components and their proximity represent what we perceive to be the amount of emphasis placed on particular indicators currently in use.

In the northern cereal belt, we can suggest a number of points about resource management indicators to assess natural, social, human, physical and financial capital.

Natural. We have many indicators representing capital assets, but many are taken for granted and some are being increasingly managed by legislation (e.g. water allocation, vegetation management controls).

Social. These are limited, although increasingly being seen as more important (i.e. triple bottom line). Research funders are insisting more on partnerships between scientists and farmers or catchment groups, to ensure more ownership and cohesiveness in developing solutions and skills.

Human: Surprisingly, this framework brings out an emphasis on improved learning, decision making and skill development in the narrow arena of agriculture and business management.

Physical. Assets that form the basis for financial transactions. Since public organisations do not often get involved in strategic decisions, this area of indicator application is poorly developed.

Financial. It is taken for granted that we have a well developed and secure financial system, and is therefore rarely considered explicitly.

In a regional setting we acknowledge other agencies and services are developing indicators for natural, social and human capital. If we take a systems approach to resource management, it seems imperative that these agencies are involved in indicator development and use with resource management practitioners. However, using a soft systems perspective, the above suggestion seems less important, given, a system is not something that actually 'exists', but is rather something a practitioner constructs to help understand and visualise relationships. Thus, a 'soft' system perspective allow us to zoom in and zoom out, discerning the boundaries of a system, and change the basis of interpretation (i.e. rather than using community capital, we could use human activity or biophysical status) depending on our purpose.

\section{Conclusions}

The application of sustainability indicators in practice is complex. Indicators are most often context, purpose and scale dependent. Traditionally, indicators have been developed to represent 'hard' system components, however, this paper illustrates the need for indicators that represent the 'soft' system. Furthermore, if sustainability is perceived as a process rather than a goal to be reached, the development of 'soft' system indicators seems even more important. To move forward in the development of indicators, we need to be more systemic about how we go about their development and use. Suggestions for improvement include: being more inclusive of all parties operating within a system, working across system boundaries (and hierarchies); and creating 'indicator systems' to aid in the understanding of indicators and where they may be of most benefit, particularly in relation to context and purpose.

\section{Acknowledgments}

We thank our colleagues in the Queensland Department of Natural Resources and Mines and the Queensland Department of Primary Industries who have provided many of the venues for the learning presented in this paper, and for those farmers who have willingly participated in focus groups and training workshops. Graeme Wockner was responsible for collecting some of the practice data presented in this paper.

\section{References}

Abbot J, Guijt I (1998) Changing views on change: participatory approaches to monitoring the environment. SARL Discussion Paper No. 2, International Institute for Environment and Development (IIED), July 1998.

Abbs K, Littleboy M (1998) Recharge estimation for the Liverpool Plains. Australian Journal of Soil Research 36, 335-357.

Cox PG, MacLeod ND, Shulman AD (1997) 'Putting sustainability into practice in agricultural research for development.' Submission to United Kingdom Systems Society 5th International Conference on Systems for Sustainability: People, Organisations and Environments, De Monfort University, July 1997.

Dalal RC, Mayer RJ (1986) Long-term trends in fertility of soils under continuous cultivation and cereal cropping in Southern Queensland. II. Total organic carbon and its rate of loss from the soil profile. Australian Journal of Soil Research 24, 281-292.

Davies S (1994) Introduction: information, knowledge and power. IDS Bulletin 25, 1-13.

Department of Natural Resources (1997) 'Salinity management handbook.' Department of Natural Resources, Brisbane.

Fairbairn B, Bold J, Fulton M, Ketilson LM, Ish D (1991) 'Co-operatives and community development: economics in social perspective.' (Houghton Boston Printers: Saskatoon)

Freebairn DM, Wockner, GH (1986) A study of soil erosion on vertisols of the eastern Darling Downs, Queensland. I. The effect of surface conditions on soil movement within contour bay catchments. Australian Journal of Soil Research 24, 135-158. 
French RJ, Shultz JE (1984) Water use efficiency of wheat in a Mediterranean-type environment. I. The relation between yield, water use and climate. Australian Journal of Agricultural Research 35, 743-764.

Hamblin A, Kyneur G. (1993) 'Trends in wheat yields and soil fertility in Australia.' Department of Primary Industries and Energy and Bureau of Resource Sciences, Canberra.

Hamilton NA (1995) 'Learning to learn with farmers.' Published Doctoral Dissertation, Wageningen Agricultural University, Wageningen, The Netherlands.

King CA (1997) Facilitating learning and creating linkages amongst farmers, researchers and scientists. In 'Conference proceedings Vol. 2, The Australasian Pacific network conference: managing change - building knowledge and skills'. November 1997, Albury.

King CA (1998) A process-analysis approach for improving multi-disciplinary farming systems research, development and extension, In 'Third European symposium on rural and farming systems analysis: environmental perspectives'. 25-27 March 1998, Germany.

King CA (2000) 'Systemic processes for facilitating social learning: challenging the legacy.' Published Doctoral Dissertation, The Swedish University of Agricultural Sciences (SLU), Uppsala, Sweden.

King CA, Gaffney J, Gunton J (2001) Does action learning make a difference? Perspectives from the Conservation Cropping Group in North Queensland, Australia. European Journal of Agricultural Extension and Education 7, 133-146.

King CA, Gunton J, Freebairn, D, Coutts J, Webb I (2000) The sustainability indicator industry: where to from here? A focus group study to explore the potential of farmer participation in the development of indicators. Australian Journal of Experimental Agriculture 40, 631-642.

Kloppenburg J (1991) Social theory and the de/reconstruction of agricultural science: local knowledge for an alternative agriculture. Rural Sociology 56, 519-548.

Lawrence DN, Cawley ST, Hayman PT (2000) Developing answers and learning in extension for dryland nitrogen management. Australian Journal of Experimental Agriculture 40, 527-539.

Molloy JM Moran CJ (1991) Compiling a field manual from overhead photographs for estimating crop residue cover. British Soil Use and Management Journal 7, 177-183.

Pannell DJ (2003) What is the value of a sustainability indicator? Economic issues in monitoring and management for sustainability. Australian Journal of Experimental Agriculture 43, 239-243.

Penman R (1994) Environmental matters and communication challenges. Australian Journal of Communication 20, 26-39.

Pretty JN (1995) Participatory learning for sustainable agriculture. World Development 23, 1247-1263.
Pretty J, Ward H (1999) Social capital and the environment. World Development 29, 209-227.

Pulsford JS (1993) Nutrient balances: Condamine-balonne-Calgoa catchments. Cited by George Rayment, Queensland Department of Natural Resources, Indooropilly.

Rendell R, O'Callaghan P, Clark N (1996) 'Families, farming and the future'. FAST Project FM500 and Sustainable Technology. Business performance indicators for farming systems in the Wimmera and Mallee of Victoria. (Neil Clark and Associates: Bendigo)

Ridge P, Bell A, Medway J, Clark N (1996) Probing water use efficiency and crop productivity in southern New South Wales, and in the Wimmera and Mallee of Victoria. In 'Families, farming and the future'. Fast Project FM500 and Sustainable Technology. (Neil Clark and Associates: Bendigo)

Ridley AM, Paramore TR, Beverly CR, Dunin FX, Froelich VMC (2003) Developing environmental monitoring tools from sustainability indicators in the southern Riverina. Australian Journal of Experimental Agriculture 43, 273-286.

Röling NG (1988) 'Extension science: information systems in agricultural development.' (Cambridge University Press: Cambridge)

Röling NG, Jiggins JLS (1994) Policy paradigm for sustainable farming, European Journal for Agricultural Research Education and Extension 1, 23-43.

Röling NG, Jiggins J (1998) The ecological knowledge system. In 'Facilitating sustainable agriculture: participatory learning and adaptive management in times of environmental uncertainty'. (Eds NG Röling, MAE Wagemakers) pp. 283-311. (Cambridge University Press: Cambridge)

Rubin HJ, Rubin IS (2001) 'Community organising and development (3rd edn).' (Allyn \& Bacon: Massachusetts)

Scoones I, Thompson J (1994) Knowledge, power and agriculture towards a theoretical understanding. In 'Beyond farmer first: rural people's knowledge, agricultural research and extension practice'. (Ed. R Chambers) (Intermediate Technology Publications: London)

Stoneham G, Eigenraam M, Ridley A, Barr N (2003) The application of sustainability concepts to Australian agriculture: an overview. Australian Journal of Experimental Agriculture 43, 195-203.

Walker J, Reuter DJ (1996) 'Indicators of catchment health: a technical perspective.' (CSIRO Publishing: Melbourne)

Received 11 December 2000, accepted 17 August 2001 